\title{
Variation of the Lateral Sacral Artery in relation to Sciatic Neuropathy
}

\author{
Waseem Al Talalwah, ${ }^{1}$ Shorok Ali Al Dorazi, ${ }^{2}$ and Roger Soames ${ }^{3}$ \\ ${ }^{1}$ Department of Basic Medical Sciences, College of Medicine, King Saud bin Abdulaziz University for Health Sciences, \\ P.O. Box 3660, Riyadh 11481, Saudi Arabia \\ ${ }^{2}$ Directorate of Prevention and Control of Healthcare Associated Infection, Eastern Province, MOH, \\ P.O. Box 411, Saihat 31972, Saudi Arabia \\ ${ }^{3}$ Centre for Anatomy and Human Identification, College of Art, Science and Engineering, University of Dundee, \\ Dundee DD1 5EH, UK
}

Correspondence should be addressed to Waseem Al Talalwah; altalalwahw@ksau-hs.edu.sa

Received 5 July 2014; Revised 20 October 2014; Accepted 30 October 2014; Published 13 November 2014

Academic Editor: Huayue Chen

Copyright (C) 2014 Waseem Al Talalwah et al. This is an open access article distributed under the Creative Commons Attribution License, which permits unrestricted use, distribution, and reproduction in any medium, provided the original work is properly cited.

\begin{abstract}
The lateral sacral artery usually originates from the posterior trunk of the internal iliac artery. The current study of 342 specimens from 171 cadavers ( 79 male, 92 female) investigated the origin and course of the lateral sacral artery. It was observed to arise from the posterior trunk in $79.1 \%$. Occasionally it originated from the anterior trunk that occurred in $1 \%$. It arose from the sciatic artery in $8.8 \%$, from the superior gluteal artery in $16.8 \%$, and from the inferior gluteal artery in $5.4 \%$. Conversely, the lateral sacral artery is congenital absence in $0.3 \%$. In addition, the lateral sacral artery was single, double, triple, and quadruple in $77.2 \%, 19.8 \%, 2.3 \%$, and $0.3 \%$, respectively. Consequently, variability of the lateral sacral artery origin is due to vascular demand as the lateral sacral artery plexus does arise from the earlier trunk development. With variability of the lateral sacral artery origin, there is a variability of the sciatic nerve supply. Knowing the variability of origins, surgeons have to avoid prolonged ligation of the internal iliac artery or its posterior trunk during surgical procedures which may lead to sciatic neuropathy. Therefore, the lateral sacral artery origin, course, and branches are important for clinicians to improve their knowledge and patient management.
\end{abstract}

\section{Introduction}

The lateral sacral artery typically arises from the posterior trunk of the internal iliac artery and then divides into superior and inferior branches. The larger superior branch passes dorsally to anastomose with the middle sacral artery giving branches to supply the contents of the sacral spinal canal, by passing through the first and second anterior sacral foramen and the skin and muscle over the dorsum of the sacral region as they exit from the first and second posterior sacral foramen. The inferior branch passes obliquely over the ventral surface of piriformis and the sacral roots of the sciatic nerve giving branches which pass through the anterior sacral foramen to supply the contents of the lower part of the sacral spinal canal and the skin and muscle over the dorsal surface of the lower sacral region $[1,2]$.
On series studies, the lateral sacral artery is found to be variable with no clear incidence of its variable origin. Knowing the incidence of variable origin of lateral sacral artery, the radiologists may alert the orthopedic surgeons to avoid iatrogenic errors such as internal hemorrhage as from lateral sacral artery laceration in internal fixation of sacrum. Therefore, the current study includes the variability of lateral sacral artery and its incidence to provide a sufficient anatomical data for clinicians, radiologists, and orthopedic surgeons to increase success rate of any surgical interferences of pelvis.

\section{Material and Method}

Present study is a dissection of 171 cadavers including 79 female and 92 male cadavers which is in total 342 hemipelves 
specimens (171 rights, 171 lefts). The age range is $37-96$ years in which the lateral sacral artery origin was investigated. The current study has been conducted in Centre for Anatomy and Human Identification, College of Life Sciences, University of Dundee in UK. It is under regulation and rule of UK research which has been approved from the Principal of anatomist. A transverse section through the abdomen above L4/L5 was made followed by sagittal sectioning of the pelvis. The peritoneum was removed after identifying the vesicouterine pouch in females and the rectovesical pouch in males. In females, the broad ligament, uterine tube, and ovary with its ligament were released and reflected from the lateral pelvic wall, while in males the vas deferens was removed or reflected superoanteriorly. The sigmoid colon was sectioned from the rectum at the rectosigmoidal junction at level of the sacral promontory, following which Waldeyer's fascia was incised to release the rectum from the pelvic wall. After removal of the pelvic fascia from the pelvic wall, as well as the endopelvic fascia, the iliac system (both venous and arterial) was exposed. At the bifurcation of the internal iliac into its anterior and posterior trunks, the lateral sacral artery could be clearly identified; its course, as well as those of its branches, was then followed and described.

\section{Results}

The lateral sacral artery was observed to have a variable origin, from the posterior trunk $(79.1 \%)$, the superior gluteal artery $(16.8 \%)$, the sciatic artery $(8.8 \%)$, the inferior gluteal artery (5.4\%), the dorsomedial side of the internal iliac artery (3.7\%), and the anterior trunk (1\%) (Table 1). In one specimen $(0.3 \%)$ it was absent, in which case the sacral sciatic nerve roots had no supply from the lateral sacral artery. The lateral sacral artery was observed to arise as a single (77.2\%), double (19.8\%), triple (2.3\%), and quadruple $(0.3 \%)$ vessel, which was absent in $0.3 \%$ (Table 2 ).

\section{Discussion}

The lateral sacral artery usually arises from the posterior trunk of the internal iliac artery [1-4]. In Polish subjects, it has been classified as being small calibre parietal branches of the internal iliac artery [5]; however Braithwaite [6] was the first to describe group variations in the origin of the parietal branches of the internal iliac artery. Within the pelvis, the arterial supply of the sciatic nerve roots, including the lumbar and sacral roots, is from the internal iliac artery via the iliolumbar, lateral sacral, and superior and inferior gluteal arteries [7]. Haller [8] noted that the roots and ganglia of the sacral nerves gained their supply from a diffuse arterial distribution. Bartholdy [9] and Tonkoff [10] both observed that the lumbar and sacral plexuses gained their supply from lumbar, iliolumbar, median, and lateral sacral arteries, as well as the gluteal and pudendal arteries. Subsequent authors including Hovelacque [11] described the distribution of the lateral sacral, median sacral, and gluteal and pudendal arteries to the sacral plexus focusing on the sciatic nerve.
TABLE 1: Origin of the lateral sacral artery.

\begin{tabular}{lc}
\hline Origin & Incidence \\
\hline Anterior trunk of the internal iliac artery & $1.0 \%$ \\
Dorsomedial aspect of the internal iliac artery & $3.7 \%$ \\
Posterior trunk of the internal iliac artery & $79.1 \%$ \\
Superior gluteal artery & $16.8 \%$ \\
Inferior gluteal artery & $5.4 \%$ \\
Internal pudendal artery & $0.3 \%$ \\
Persistent sciatic artery & $8.8 \%$ \\
Congenital absence & $0.3 \%$ \\
\hline
\end{tabular}

The lateral sacral artery commonly arose from the posterior trunk of the internal iliac artery. Occasionally, it arose from different arteries. Observations are based on 342 specimens.

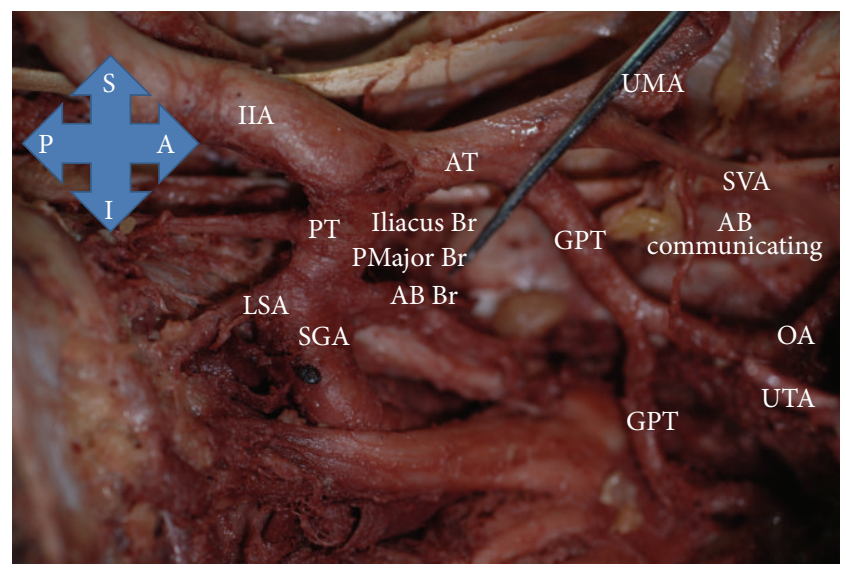

FIGURE 1: The lateral sacral artery arising from the posterior trunk of the internal iliac artery (IIA: internal iliac artery; AT: anterior trunk; PT: posterior trunk; UMA: umbilical artery; SVA: superior vesical artery; IPA: internal pudendal artery; LSA: lateral sacral artery; OA: obturator artery; GPT: gluteopudendal trunk; SGA: superior gluteal artery; UTA: uterine artery; AB branch: anomalous branch; $\mathrm{AB}$ communicating: anomalous branch communicating; iliacus $\mathrm{Br}$ : iliacus branch; PMajor Br: psoas major branch).

Based on a three-dimensional angiographic study of the internal iliac artery, Naguib et al. [12] reported that the lateral sacral artery was present in $88 \%$ of specimens examined. They also observed that it mainly arose not only from the posterior trunk (91\%) but also from the internal iliac artery (7\%) and the anterior trunk (1\%), as well as from the inferior gluteal artery when it arose from the posterior trunk. This variability of origin is said to be due to development reasons [13].

Each lateral sacral artery usually divides into superior and inferior branches (Figure 1), with the superior branch passing through the upper two anterior sacral foramina, while the inferior branch takes a diagonal course over the ventral surface of piriformis and the sciatic nerve sacral roots (Figure 2) before entering the lower anterior sacral foramina. The artery anastomoses with the median sacral artery and contralateral lateral sacral artery at the level of the coccyx $[1,2]$. Sharpey et al. [14] described the lateral sacral artery as having ventral and dorsal branches, of which the ventral branches supply piriformis and the sacral nerve roots 
TABLE 2: The incidence of the lateral sacral arteries number observed in series studies and current study.

\begin{tabular}{lcccccc}
\hline Number $\backslash$ study & Tonkoff [10] & Naguib et al. [12] & Sadler [13] & Sharpey et al. [14] & Poynter [15] & Current study \\
\hline Single & $0 \%$ & $30 \%$ & $55 \%$ & $26 \%$ & $50 \%$ & $77.2 \%$ \\
Double & $98 \%$ & $48 \%$ & $45 \%$ & $61.5 \%$ & $42.5 \%$ & $19.8 \%$ \\
Triple & $2 \%$ & $9 \%$ & $0 \%$ & $11 \%$ & $7.5 \%$ & $2.3 \%$ \\
Quadruple & $0 \%$ & & $0 \%$ & $1.5 \%$ & $0.3 \%$ \\
\hline
\end{tabular}

The lateral sacral artery commonly arose from the internal iliac artery in different numbers but was found to be absent in one specimen. Observations are based on 342 specimens.

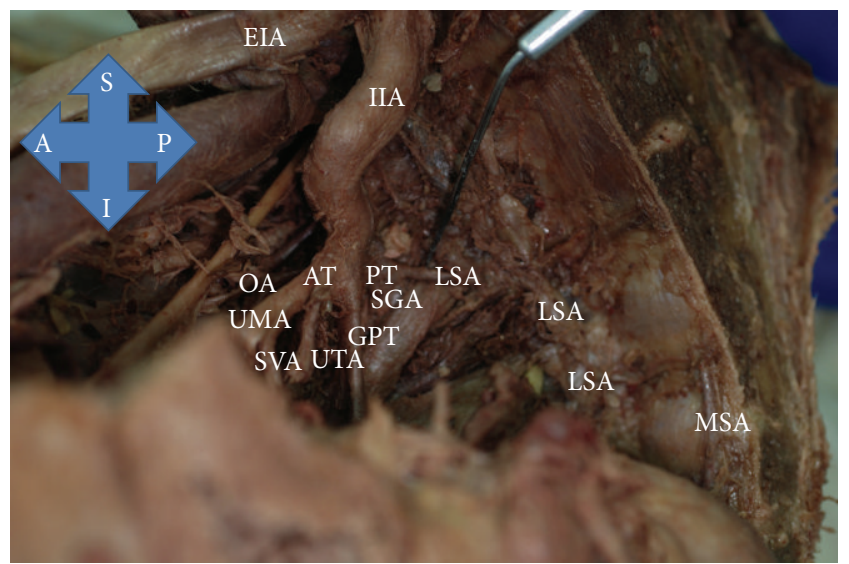

Figure 2: The inferior branch of the lateral sacral artery passing over the sacral convexity supplying the ventral surface of piriformis and the sacral roots of the sciatic nerve by several tiny branches (IIA: internal iliac artery; AT: anterior trunk; PT: posterior trunk; UMA: umbilical artery; SVA: superior vesical artery; IPA: internal pudendal artery; LSA: lateral sacral artery; OA: obturator artery; GPT: gluteopudendal trunk; SGA: superior gluteal artery; UTA: uterine artery; MS: middle sacral artery).

terminating by anastomosing with the middle sacral artery, while the dorsal branches curve posteriorly to supply the contents of the spinal canal via the anterior sacral foramen, continuing their course through the posterior sacral foramina to supply the skin and muscle over the dorsal surface of the sacrum.

The lateral sacral artery is considered to be the main arterial supply to the sciatic nerve in the pelvic region; however with a variable origin there may also be a variable supply to the sacral sciatic nerve roots during its course. In an early report, Poynter [15] observed the lateral sacral artery arising from the internal iliac artery in $22 \%$ of specimens; in the present study when the lateral sacral artery arose from the dorsomedial side of the internal iliac artery it supplied all sacral sciatic nerve roots during its course (Figure 3 ). When the artery arose from the anterior (Figure 4) or posterior trunk it also supplied all sciatic nerve roots, except the lumbosacral trunk as was the case when the lateral sacral artery arose from the sciatic artery (Figure 5) or from the superior gluteal artery (Figure 6). However, when the lateral sacral artery arose from the inferior gluteal artery it supplied the lower two sciatic sacral roots only (Figure 7). It appears that, except in rare cases, the lateral sacral artery is the only artery directly supplying the sciatic nerve roots.

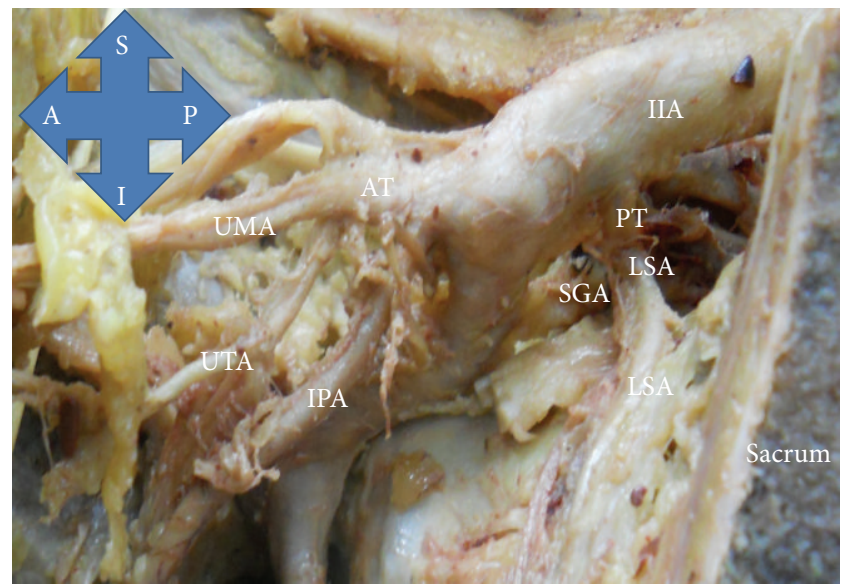

FIGURE 3: The lateral sacral artery arising from the dorsomedial side of the internal iliac artery supplying all sciatic nerve roots during its course (IIA: internal iliac artery; AT: anterior trunk; PT: posterior trunk; UMA: umbilical artery; IPA: internal pudendal artery; LSA: lateral sacral artery).

In the study by Naguib et al. [12] as well as from the observations of this dissection based study, the lateral sacral artery most frequently arises from the posterior trunk of the internal iliac artery. Presentation of the lateral sacral artery origin from the anterior trunk occurred in $1 \%$ of specimens when the anterior trunk compensated for the posterior trunk. These variations can be explained by the development of the sciatic artery. Due to vascular demand, the lateral sacral artery plexus does not arise from the dorsal aspect of the primitive axial artery due to a delay in posterior trunk development and early anterior trunk development. In addition, the lateral sacral artery arising directly $[12,15]$ or indirectly [16] from the internal iliac artery is due to regression of the sciatic artery and development of internal iliac artery associated with a delay in the development of its trunks. The primitive axial artery therefore regresses as the primitive lateral sacral artery develops and continues to bud to supply tissue to provide sufficient vascularisation. Consequently, there is variability of the origin of the lateral sacral artery due to vascular demand sciatic tissue controlling the regression and development of its primitive plexus (Figure 8).

In a previous study [17], the lateral sacral artery was found to be a double in $98 \%$ of specimens and a triple artery in $2 \%$ of specimens. More recently [15], it was reported to be a single in $55 \%$ and double in $45 \%$ of specimens. In the current study, the majority (77.2\%) of lateral sacral arteries arose 


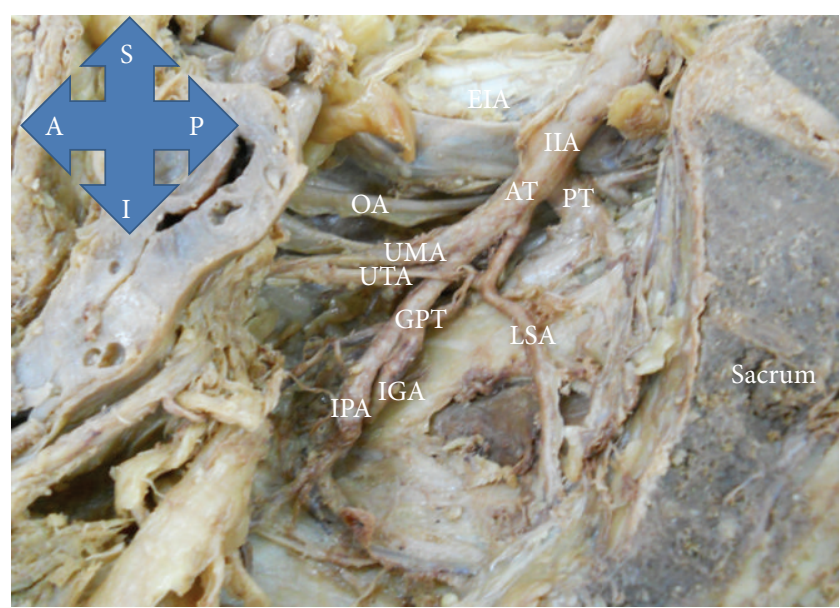

FIGURE 4: Lateral sacral artery arising from the anterior trunk of the internal iliac artery (IIA: internal iliac artery; AT: anterior trunk; PT: posterior trunk; UMA: umbilical artery; UTA: uterine artery; OA: obturator artery; GPT: gluteopudendal trunk; IGA: inferior gluteal artery; IPA: internal pudendal artery; SGA: superior gluteal artery; LSA: lateral sacral artery).

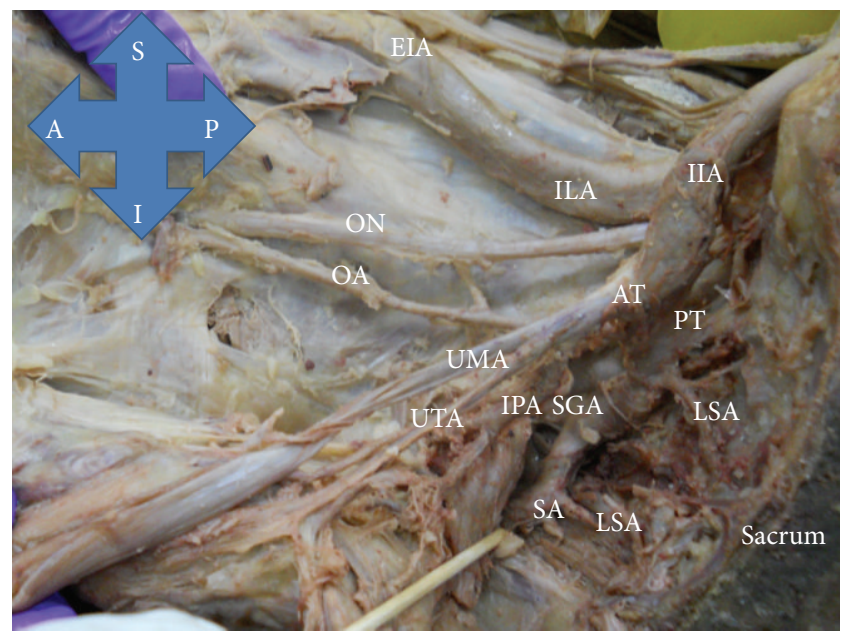

FIGURE 5: Lateral sacral artery arising directly from the posterior trunk and indirectly from the sciatic artery (EIA: external iliac artery; IIA: internal iliac artery; AT: anterior trunk; PT: posterior trunk; UMA: umbilical artery; OA: obturator artery; ON: obturator nerve; UTA: uterine artery; IPA: internal pudendal artery; SGA: superior gluteal artery; SA: sciatic artery; LSA: lateral sacral artery).

as single vessels, with double, triple, and quadruple vessels observed in $19.8 \%, 2.3 \%$, and $0.3 \%$ of specimens, respectively. The number of lateral sacral arteries present can be explained by the vascular demand of tissues supplied.

From the current study it is clear that the lateral sacral artery supplies the sacral roots during its course. However, the possibility of lateral sacral artery aneurysm associated with thrombosis [18] would create direct pressure and/or impairment of the collateral circulation $[19,20]$ to the sciatic nerve roots potentially giving rise to radiculopathy or acute low back pain [18]. Moreover, prolonged ligation of the

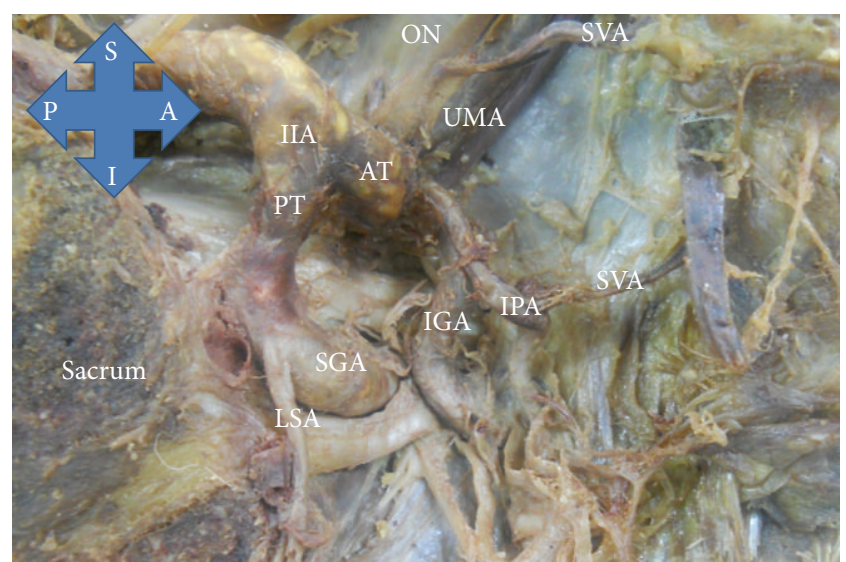

FIgURE 6: Lateral sacral artery arising from the superior gluteal artery (IIA: internal iliac artery; AT: anterior trunk; PT: posterior trunk; UMA: umbilical artery; SVA: superior vesical artery; IPA: internal pudendal artery; LSA: lateral sacral artery; OA: obturator artery; SGA: superior gluteal artery; IGA: inferior gluteal artery).

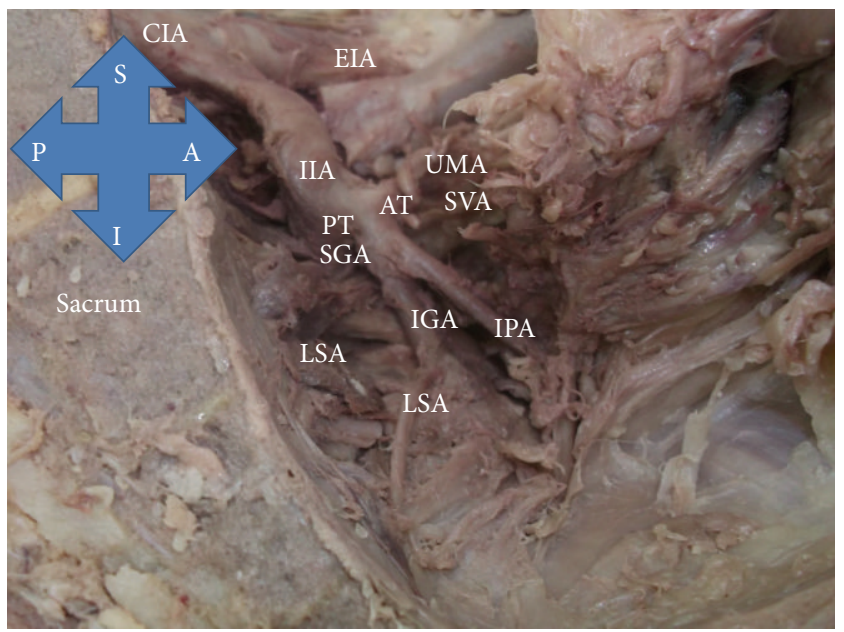

FIGURE 7: Lateral sacral artery arising from inferior gluteal artery (IIA: internal iliac artery; AT: anterior trunk; PT: posterior trunk; UMA: umbilical artery; SVA: superior vesical artery; IPA: internal pudendal artery; LSA: lateral sacral artery; SGA: superior gluteal artery; IGA: inferior gluteal artery).

internal iliac artery and its trunk may reduce the blood supply to the sciatic sacral nerve roots leading to sciatic neuropathy presenting with sciatic symptoms [18-21].

Internal pelvic haemorrhage may occur due to posterior pelvic (sacral) fracture as a result of lateral sacral artery laceration. Furthermore, the variability in origin of the lateral sacral artery should be considered by orthopaedic surgeons as a potential risk factor associated with internal pelvic haemorrhage during sacral screw fixation.

\section{Conclusion}

As the lateral sacral artery supplies the sacral roots during its course, sciatic neuropathy may occur due to ischemia, due 


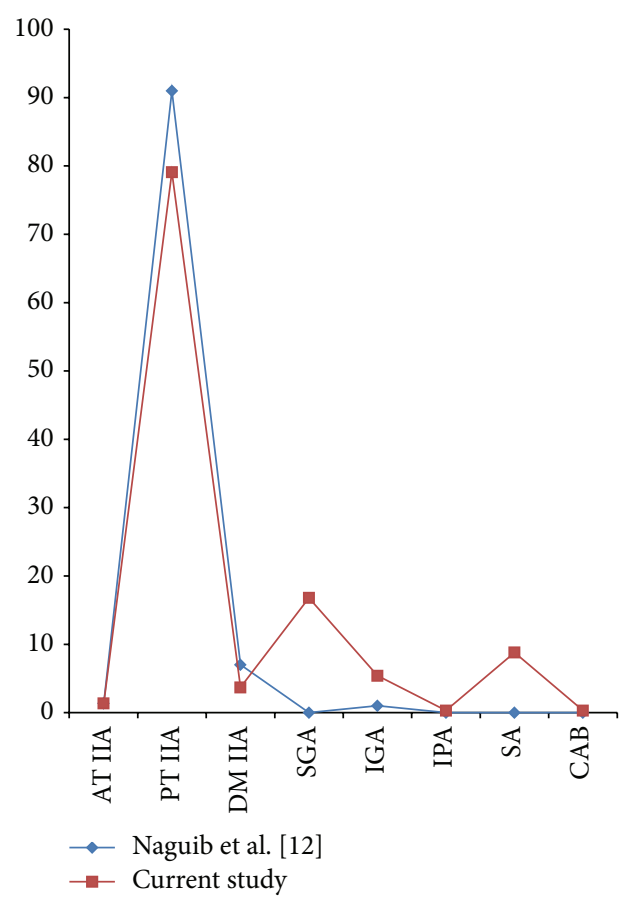

FIGURE 8: A comparison of the lateral sacral artery origin. Naguib et al. study [12] is a radiologic study and includes 86 cases, whereas the current study is an anatomical study and includes 342 cases (AT: anterior trunk; DM IIA: dorsomedial side of internal iliac artery; PT: posterior trunk; SGA: superior gluteal artery; IGA: inferior gluteal artery; IPA: internal pudendal artery; SA: sciatic artery).

to either thrombotic aneurysm of the lateral sacral artery or aneurysmal mass compression. Therefore, the lateral sacral artery origin, course, and branches are important for clinician to improve their knowledge and patient management.

\section{Conflict of Interests}

The authors declare that there is no conflict of interests regarding the publication of this paper.

\section{Acknowledgments}

The authors would like to thank the donors of cadavers which have been used in this research study. Also, they would like to thank all the employees working in Centre for Anatomy and Human Identification as well as King Saud bin Abdulaziz University for Health Sciences for providing the necessary facilities for the preparation of the paper.

\section{References}

[1] H. Carter, Anatomy Descriptive and Surgical, Blanchard and Lea, Philadelphia, Pa, USA, 1867.

[2] E. Wilson, A System of Human Anatomy, General and Special, Lea and Blanchard, Philadelphia, Pa, USA, 7th edition, 1868.

[3] J.-P. Pelage, O. Le Dref, P. Soyer et al., "Arterial anatomy of the female genital tract: variations and relevance to transcatheter embolization of the uterus," American Journal of Roentgenology, vol. 172, no. 4, pp. 989-994, 1999.

[4] S. Reddy, V. R. Vollala, and M. Rao, "Absence of inferior gluteal artery: a rare observation," International Journal of Morphology, vol. 25, no. 1, pp. 95-98, 2007.

[5] S. Jastschinski, "Die typischen verzweigungsformen der arteria hypogastria," Internationale Monatsschrift für Anatomie und Physiologie, vol. 8, pp. 111-127, 1891.

[6] J. L. Braithwaite, "Variations in origin of the parietal branches of the internal iliac artery," Journal of Anatomy, vol. 86, no. 4, pp. 423-430, 1952.

[7] M. H. Day, "The blood supply of the lumbar and sacral plexuses in the human foetus," Journal of Anatomy, vol. 98, no. 1, pp. 105116, 1964.

[8] A. Haller, Icones anatomicae in quibus aliquae partes corporis humani delineatae proponuntur et arteriarum potissimum historia continetur, Vandenhoeck, Göttingen, Germany.

[9] K. Bartholdy, "Die arterien der nerven," Morphologische Arbeiten, vol. 7, pp. 393-458, 1897.

[10] W. Tonkoff, "Die Arterien der Intervertebralganglion und der Cerebrospinalnerven des Menschen," Int Mschr Anat Physiol, vol. 15, pp. 353-401, 1898.

[11] A. Hovelacque, Anatomie des Nerfs Craniens et Rachidiens et du Systeme Grand Sympathique, Doin, Paris, France, 1927.

[12] N. N. N. Naguib, N.-E. A. Nour-Eldin, R. M. Hammerstingl et al., "Three-dimensional reconstructed contrast-enhanced MR angiography for internal iliac artery branch visualization before uterine artery embolization," Journal of Vascular and Interventional Radiology, vol. 19, no. 11, pp. 1569-1575, 2008.

[13] T. W. Sadler, Langman's Medical Embryology, Williams \& Wilkins, London, UK, 6th edition, 1990.

[14] W. Sharpey, A. Thomson, and J. Cleland, Quain's Elements of Anatomy, pp. 418-442, Longmans, Green and Co, London, UK, 7th edition, 1867.

[15] C. W. M. Poynter, "Congenital anomalies of the arteries and veins of the human body of man with bibliography," University Studies of the University of Nebraska, vol. 22, pp. 1-106, 1922.

[16] S. N. Badagabettu, N. Kumar, S. D. Shetty, and S. R. Sirasanagandla, "Variant branching pattern of the right internal iliac vessels in a male-a case report," Archives of Clinical and Experimental Surgery, vol. 3, no. 3, pp. 197-200, 2014.

[17] F. G. Parsons and A. Keith, "Sixth annual report of the Committee of Collective Investigation of the Anatomical Society of Great Britian and Ireland (1895-96)," Journal of Anatomy \& Physiology, vol. 31, pp. 31-44, 1895.

[18] C. D. Alberstone, F. W. Rupp, and J. A. Anson, "Spinal aneurysm of the lateral sacral artery: case report," Journal of Neurosurgery, vol. 92, no. 1, pp. 101-104, 2000.

[19] A. Koçak, Ö. Ateş, S. R. Çayli, and K. Saraç, "Isolated posterior spinal artery aneurysm," British Journal of Neurosurgery, vol. 20, no. 4, pp. 241-244, 2006.

[20] M. G. Massanda, R. C. Wallacea, L. F. Gonzalezb, J. M. Zabramskib, and R. F. Spetzlerb, "Subarachnoidhemorrhage due to isolated spinal artery aneurysm in four patients," The American Journal of Neuroradiology, vol. 26, pp. 2415-2419, 2005.

[21] O. J. Yano, N. Morrissey, L. Eisen et al., "Intentional internal iliac artery occlusion to facilitate endovascular repair of aortoiliac aneurysms," Journal of Vascular Surgery, vol. 34, no. 2, pp. 204211, 2001. 

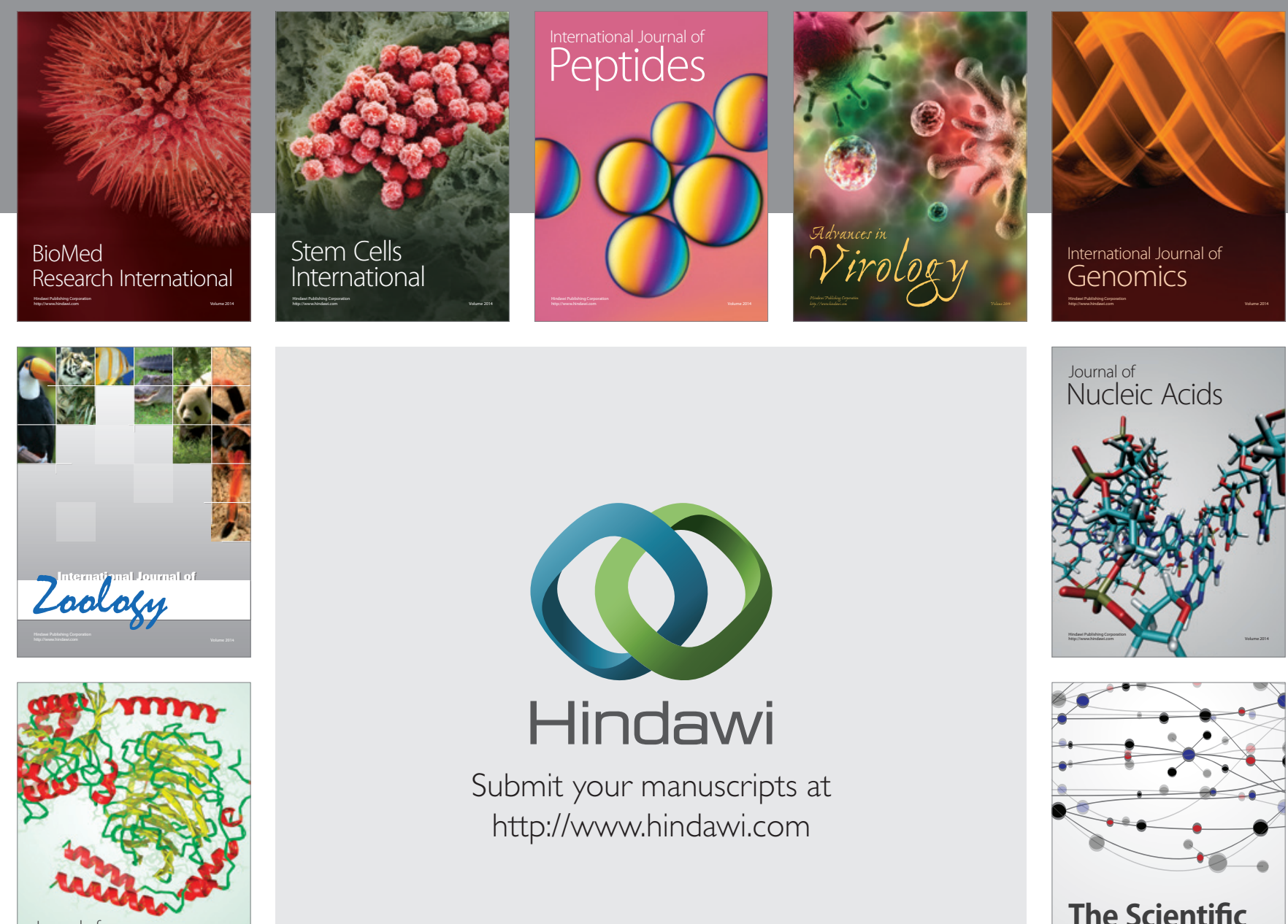

Submit your manuscripts at

http://www.hindawi.com

Journal of
Signal Transduction
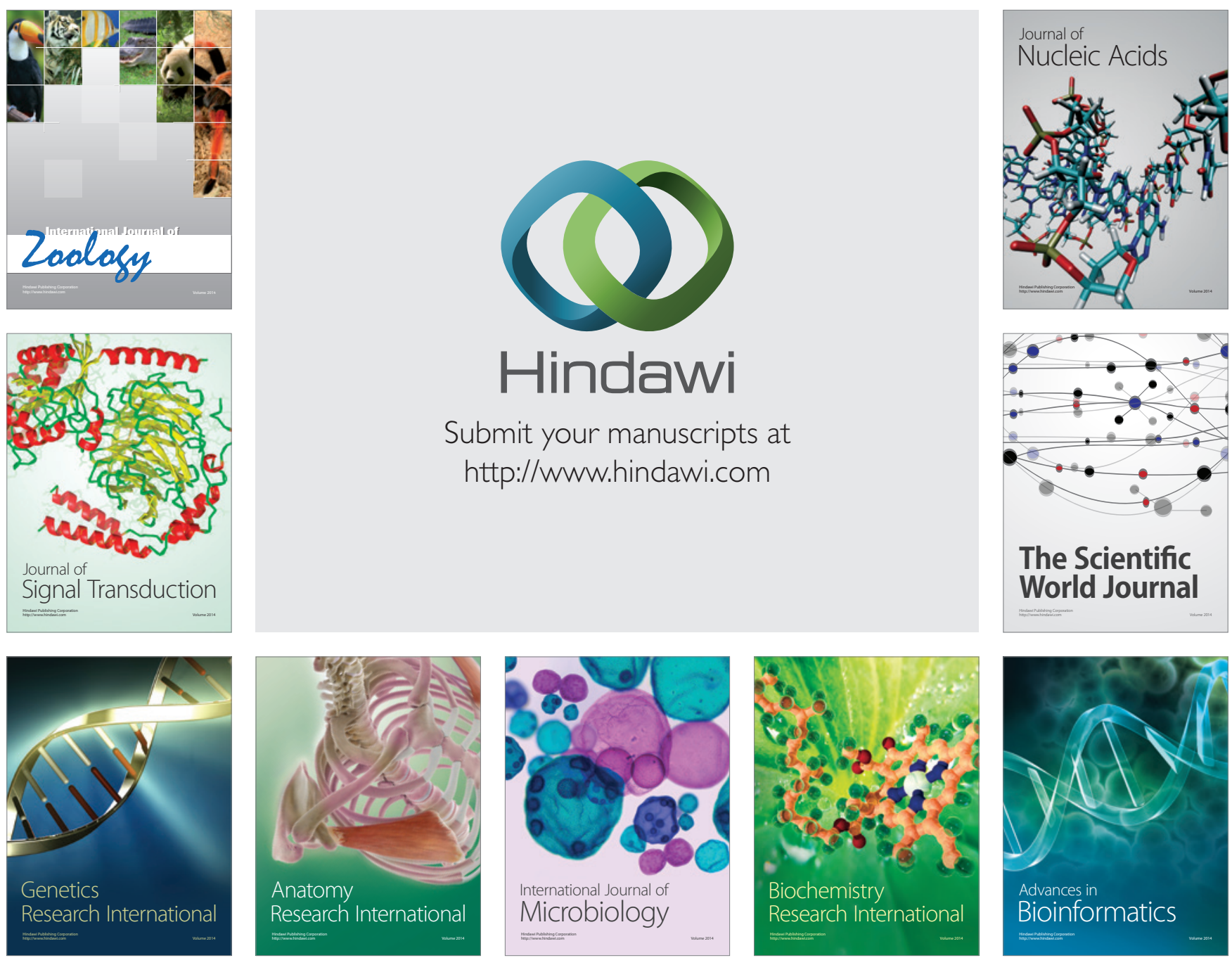

The Scientific World Journal
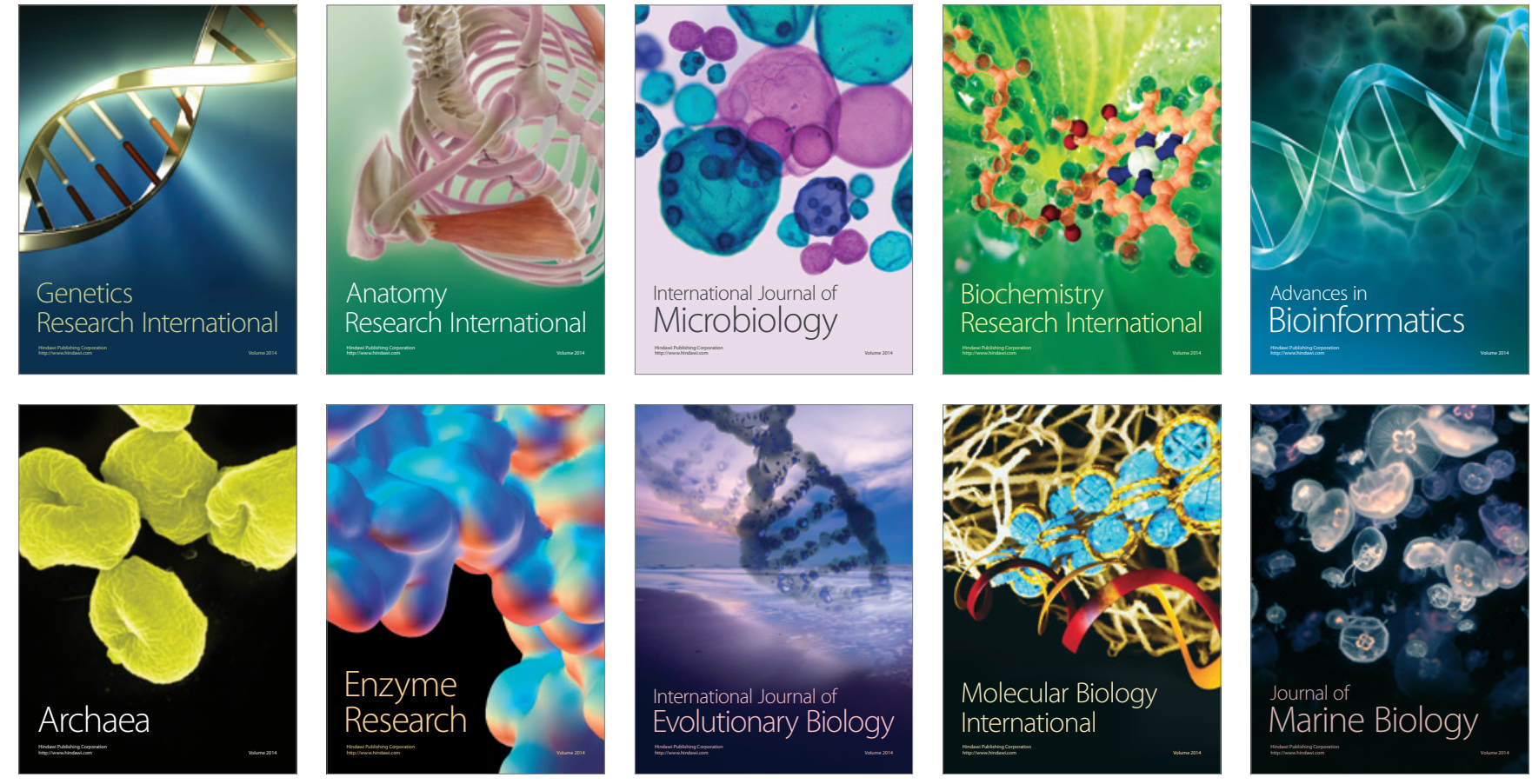